\title{
The effect of storage on the colour of paprika powders with added oleoresin
}

\author{
Zs. H. Horváth \\ e-mail: horvatzs@mk.u-szeged.hu \\ University of Szeged, Faculty of Engineering, \\ 6725 Moszkvai krt. 9., Szeged, Hungary
}

\begin{abstract}
The use of natural food colours is preferred to that of artificial dyestuffs for modern alimentary purposes. Paprika is a spice plant grown and consumed in considerable quantities worldwide and also used as a natural food colour, so the colouring power of powders is very important. The colour of paprika powder is highly relevant too because the consumer concludes its colouring power based on its colour. The colouring power of paprika powders is directly determined by the quality and quantity of the colouring agent of paprika. The paprika oleoresin, that is an oil soluble extract from the fruits of Capsicum Annum Linn or Capsicum Frutescens, is suitable to raise the colour agent content of paprika powders. We investigated how the colour and the characteristics of paprika powder samples with added oleoresin change in the course of storage. The colour agent content of 7 different quality powders was increased with $7-75 \%$ using oleoresin. The initial colour agent content of samples changed between 41 and 169 ASTA units. The powders were made from Chinese, Peruvian, and Hungarian paprika. Colour measurements were performed with a HunterLab MiniScan colour-measuring instrument. The CIELab colour system was used for colour characterization. The colour agent content and the colour coordinates of samples were measured throughout 9 months. The decrease of colour agent content varied between 22 and 51 percent, while the average reduction was 33 percent. The quantity of added oleoresin did not influence the colour agent content decrease significantly.
\end{abstract}

Keywords and phrases: paprika powder, colour, storage 
The effect of storage on the colour of paprika powders with added oleoresin 51

The values of colour difference changed between 2 and 4.5 units. The initial paprika powder influenced the variation significantly, but the quantity of added oleoresin did not have a significant effect.

\section{Introduction}

The use of natural food colours is preferred to that of artificial dyestuffs for modern alimentary purposes. Paprika is a spice plant grown and consumed in considerable quantities worldwide, and also used as a natural food colour. The colouring power of paprika powders is directly determined by the quality and quantity of the colouring agent of paprika. The colour agent content of powders decreases during storage time and it is influenced by the stages of the processing. Dehydration is the most critical step of the processing. The effect of the heat impairs the colour agent, aroma, and flavour substratum of paprika. Several researchers investigated the optimal parameters of dehydration (Minguez-Mosquera et al., 2000; Ramesh et al., 2001; Shin et al., 2001; Doymaz \& Pala, 2002; Kim et al., 2004; Perez-Gamez et al., 2005; Simal et al., 2005). Topuz et al. (2011) compared the Refractance Window (RWD) method to dry paprika in comparison with freeze-drying, hot-air oven drying, and natural convective drying methods. It was pointed out that the least colour agent content decrease was in the case of the natural convective drying method. Colour agent content reduction is effected by storage conditions. There are many studies on the changes in the colour agent content of the paprika storage processes (Park et al., 2007, Banout et al., 2011, Topaz et al., 2011, Chetti et al., 2012).

The colour of the powder is influenced by many factors besides the colouring agent content. The colour of the powder is influenced by its particle size, oil and moisture content, but first of all by the colour agent content. The instrumental colour measurement is not used in industrial practice - the development of the colour of the paprika powder is made based on the empirical facts; therefore, the quantity of the colour of the end-product is often not correct.

Since the 1970s, a number of papers have been published on measurements of the colour of paprika powders (Horváth \& Kaffka, 1973; Drdak et al., 1989). Measurements have been performed relating to the correlation between visual sensing and the instrumentally measured colour characteristics (Huszka et al., 1985, Horváth, 2007). The effects of ionizing irradiation on the colour of paprika powder were investigated by Fekete-Halász et al. (1996). Minguez et al. (1997) analysed how the colour of the powder is changed by the ratio of 
the yellow and red pigments within the total colouring agent content. There are many papers about the changes in the colour characteristics of the paprika during different drying and storing processes (Park et al., 2007, Banout et al., 2011, Topaz et al., 2011, Chetti et al., 2012). In the case of the Korean cultivars, no significant change in colour characteristics was detected when the moisture content varied between $10 \%$ and $15 \%$ (Chen et al., 1999). Horváth \& Hodúr (2007) investigated Hungarian paprika powders, and pointed out that the colour of the powder was observed to be turning into darker and deeper red while increasing moisture content. Various investigations have been made on the connection between the colouring agent content of the powder and the colour characteristics measured by different techniques (Navarro et al., 1993, Nieto-Sandoval et al., 1999). Such investigations have yielded partial results, but there is no formula that describes the correlation between the colouring agent content and the colour characteristics.

The paprika oleoresin, that is an oil soluble extract from the fruits of Capsicum Annum Linn or Capsicum Frutescens, is often used to increase the colour agent content of paprika powders. We investigated how the colour agent content and the colour of paprika powder samples with added oleoresin change during storage time.

\section{Materials and method}

\subsection{Materials}

The colour agent content of 7 different quality powders was increased. The initial colour agent content of the samples changed between 41 and 169 ASTA units. The powders were made from Chinese, Peruvian, and Hungarian paprika. The colour agent content was increased using $0.5-3.0$ g oleoresin added to 100 g paprika powder.

\subsection{Measurement of colour agent content}

After homogenization of powders, the colour agent content of samples was measured. The ASTA (American Spice Trade Association) unit was used to measure the colour agent content of paprika powders according to MSZ EN ISO 7541. The acetone extracts of paprika powder were measured by photometer at $460 \mathrm{~nm}$. The ASTA unit was calculated using the following formula:

$$
\mathrm{ASTA}=\frac{\text { Absorbance } \cdot 16,4 \cdot \mathbf{f}}{\text { weight of sample }(\mathrm{g})}
$$


The effect of storage on the colour of paprika powders with added oleoresin 53

where $\mathbf{f}$ is a correction factor for the used photometer.

\subsection{Measurement of colour}

Colour measurements were performed with a HunterLab MiniScan colourmeasuring instrument. The CIELab colour system was used for colour characterization. In this colour space, the colour points are characterized by three colour coordinates. $\mathrm{L}^{*}$ is the lightness coordinate ranging from no reflection for black $\left(L^{*}=0\right)$ to perfect diffuse reflection for white $\left(L^{*}=100\right) \cdot a^{*}$ is the redness coordinate ranging from negative values for green to positive values for red. $\mathrm{b}^{*}$ is the yellowness coordinate ranging from negative values for blue and positive values for yellow.

The total colour change is given by the colour difference $\left(\Delta \mathrm{E}_{\mathrm{ab}}^{*}\right)$ in terms of the spatial distance between two colour points interpreted in the colour space (Hunter, 1987):

$$
\Delta \mathrm{E}_{\mathrm{ab}}^{*}=\left[\left(\mathrm{L}_{1}^{*}-\mathrm{L}_{2}^{*}\right)^{2}+\left(\mathrm{a}_{1}^{*}-\mathrm{a}_{2}^{*}\right)^{2}+\left(\mathrm{b}_{1}^{*}-\mathrm{b}_{2}^{*}\right)\right]^{1 / 2} .
$$

If $1.5<\Delta \mathrm{E}_{\mathrm{ab}}^{*}<3$, then the colour difference between two paprika grists can hardly be visually distinguished; if $\Delta \mathrm{E}_{\mathrm{ab}}^{*}>3$, then the colour difference between two paprika grists can be visually distinguished (Horváth, 2007).

The chroma $\left(\mathrm{C}_{\mathrm{ab}}^{*}\right)$ was used to determine the change of colour:

$$
\mathrm{C}_{\mathrm{ab}}^{*}=\left(\left(\mathrm{a}^{*}\right)^{2}+\left(\mathrm{b}^{*}\right)^{2}\right)^{\frac{1}{2}} .
$$

The chroma represents colour saturation, which varies from dull at low chroma values to vivid colour at high chroma values (Hunter, 1987). The samples were stored at room temperature, protected from light. The colour coordinates and colour agent content were measured monthly for 5 months, and after 7 months and 9 months.

\section{Results}

\subsection{Changes of the colour agent content}

To evaluate the changes of colour agent content, we calculated the value of the decrease of colour agent content measured at different times, correlated to the initial value. The values were given in percentage. First, we analysed how the colour agent content decreased throughout 9 months, influenced by the initial paprika samples and the quantity of added oleoresin. The ANOVA was applied. The results of ANOVA is shown in Table 1. 
Table 1: Variance table in the case of colour agent content decrease throughout 9 months

\begin{tabular}{lcc}
\hline \multicolumn{1}{c}{ Factor } & F value & Significant level \\
\hline Quantity of added oleoresin & 0.72 & 0.54 \\
Initial paprika powder & 31.99 & 0.00 \\
\hline
\end{tabular}

It can be established that the quantity of added oleoresin did not influence the colour agent content decrease significantly, but the initial paprika powder affected it significantly. In Figure 1, we can see the averages decrease with confidence interval at a level of $95 \%$.

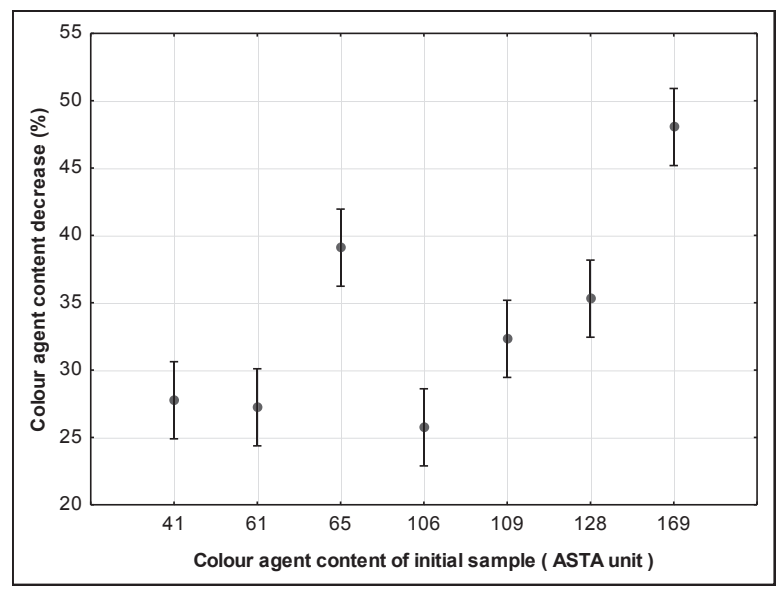

Figure 1: Results of ANOVA for colour agent content decrease throughout 9 months (average with confidence interval at a level of 95\%)

The decrease of the colour agent content varied between 22 and 51 percent. It can be seen well that the decrease was valid mostly in the case of Hungarian paprika powders (65 ASTA, 128 ASTA, and 169 ASTA) and the loss was small for Peruvian powders.

\subsection{The change of the colour characteristics}

To evaluate the change of colour, we calculated the $\Delta \mathrm{E}_{\mathrm{ab}}^{*}$ colour difference values between colour coordinates measured at first and measured during storage. The values for the different samples are shown in figures $2-4$. We can see that 
the values of colour difference for initial samples $(0 \mathrm{~g})$ and the values of colour difference for samples with added oleoresin do not differ significantly.

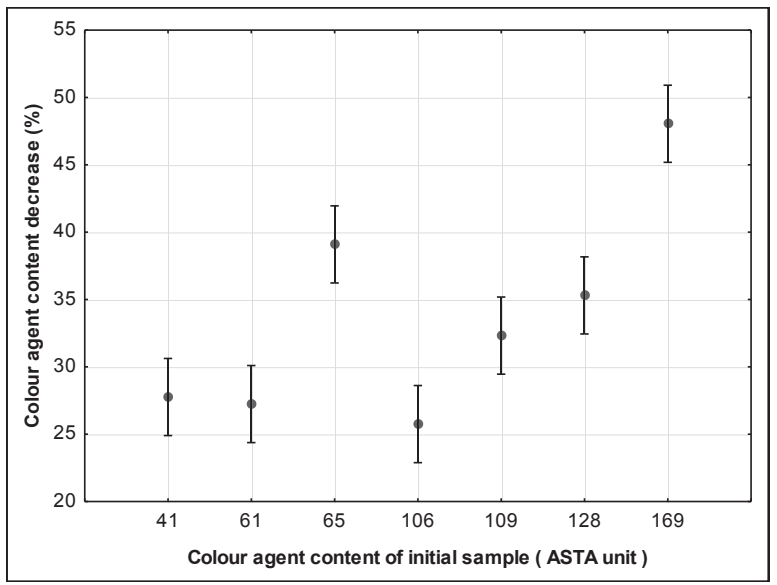

Figure 2: $\Delta \mathrm{E}_{\mathrm{ab}}^{*}$ colour differences calculated between colour coordinates measured at first and during storage time in the case of Hungarian samples

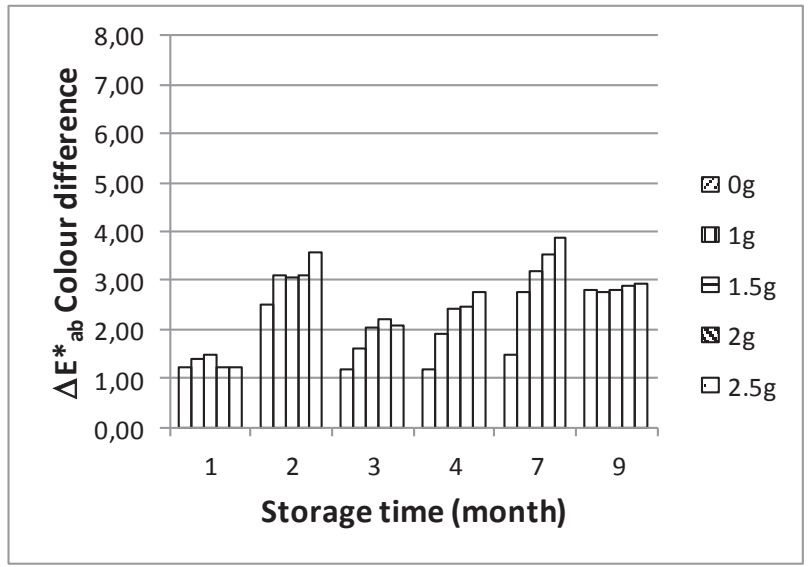

Figure 3: $\Delta \mathrm{E}_{\mathrm{ab}}^{*}$ colour differences calculated between colour coordinates measured at first and during storage time in the case of Chinese samples

Colour difference values exceeded the perceptible 3 units after 7 months in the case of samples made of Hungarian paprika and in the case of Chinese paprika samples. Colour differences were less than 3 units for all samples in the case of Peruvian paprika. 


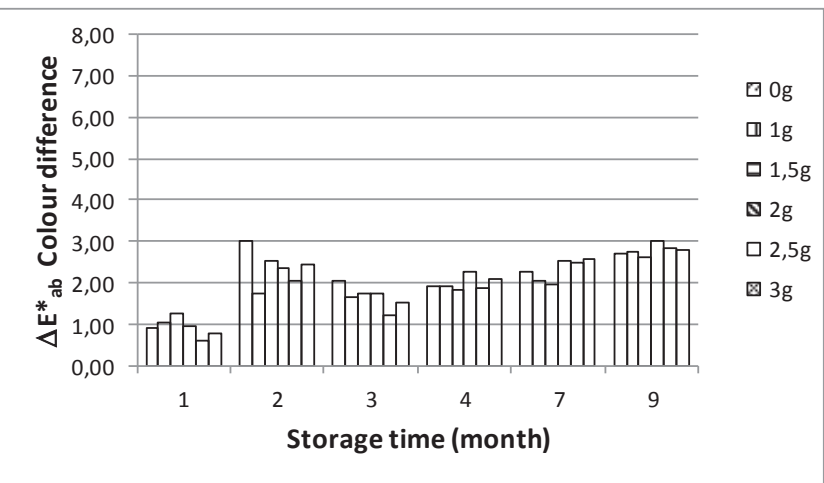

Figure 4: $\Delta \mathrm{E}_{\mathrm{ab}}^{*}$ colour differences calculated between colour coordinates measured at first and during storage time in the case of Peruvian samples

Table 2: $\Delta \mathrm{L}$ lightness coordinate differences calculated between colour coordinates measured the first time and during storage

\begin{tabular}{|c|c|c|c|c|c|c|c|c|}
\hline \multicolumn{9}{|c|}{ Storage time (month) } \\
\hline $\begin{array}{l}\text { Initial } \\
\text { sample }\end{array}$ & $\begin{array}{l}\text { Added } \\
\text { oleoresin } \\
(\mathrm{g})\end{array}$ & 1 & 2 & 3 & 4 & 5 & 7 & 9 \\
\hline \multirow{5}{*}{ Hungarian } & 0.0 & -1.12 & -1.04 & -1.15 & -2.36 & -1.87 & -2.64 & -3.52 \\
\hline & 0.5 & -0.83 & -1.57 & -1.91 & -2.67 & -1.69 & -3.2 & -3.58 \\
\hline & 1.0 & -0.82 & -1.56 & -2.06 & -2.36 & -1.36 & -3.12 & -3.52 \\
\hline & 1.5 & -1.17 & -1.86 & -2.12 & -2.51 & -1.46 & -3.25 & -3.45 \\
\hline & 2.0 & -1.22 & -1.51 & -2.30 & -2.78 & -1.62 & -3.53 & -3.70 \\
\hline \multirow{5}{*}{ Chinese } & 0.0 & 0.25 & -0.47 & 0.15 & -0.15 & -0.06 & 0.71 & -1.23 \\
\hline & 1.0 & -0.18 & -0.40 & -0.33 & -0.45 & -0.63 & -0.27 & -0.80 \\
\hline & 1.5 & -0.47 & -0.78 & -0.54 & -0.60 & -0.85 & -0.39 & -1.04 \\
\hline & 2.0 & -0.80 & -0.94 & -0.80 & -1.20 & -1.27 & -1.05 & -1.25 \\
\hline & 2.5 & -1.09 & -0.90 & -0.55 & -1.04 & -1.31 & -1.00 & -1.30 \\
\hline \multirow{6}{*}{ Peruvian } & 0.0 & -0.47 & -1.87 & -1.32 & -0.93 & -1.40 & -1.81 & -1.47 \\
\hline & 1.0 & -0.75 & -1.06 & -1.07 & -1.53 & -1.60 & -1.76 & -1.90 \\
\hline & 1.5 & -0.58 & -1.15 & -1.15 & -1.21 & -1.29 & -1.80 & -1.86 \\
\hline & 2.0 & -0.89 & -1.80 & -1.44 & -1.98 & -2.10 & -2.18 & -2.43 \\
\hline & 2.5 & -0.54 & -1.62 & -1.08 & -1.69 & -2.24 & -2.23 & -2.40 \\
\hline & 3.0 & -0.73 & -1.91 & -1.40 & -1.83 & -2.33 & -1.96 & -2.34 \\
\hline
\end{tabular}


The effect of storage on the colour of paprika powders with added oleoresin 57

In Table 2, we present $\Delta \mathrm{L}$ lightness coordinate differences calculated between colour coordinates measured at first and during storage. The values are negative, so the colour of powders became brighter during storage. In Table 3 , we can see $\mathrm{C}_{\mathrm{ab}}^{*}$ chroma calculated between colour coordinates measured at first and during storage time. The values are positive, so the colour of powders became less saturated during storage.

Table 3: $\mathrm{C}_{\mathrm{ab}}^{*}$ chroma differences calculated between colour coordinates measured the first time and during storage time

\begin{tabular}{|c|c|c|c|c|c|c|c|c|}
\hline \multicolumn{9}{|c|}{ Storage time (month) } \\
\hline $\begin{array}{l}\text { Initial } \\
\text { sample }\end{array}$ & $\begin{array}{l}\text { Added } \\
\text { oleoresin } \\
(\mathrm{g})\end{array}$ & 1 & 2 & 3 & 4 & 5 & 7 & 9 \\
\hline \multirow{5}{*}{ Hungarian } & 0.0 & 1.58 & 0.78 & 0.72 & 1.89 & 0.83 & 2.29 & 1.17 \\
\hline & 0.5 & 0.62 & 0.82 & 0.81 & 1.31 & -0.41 & 1.95 & 0.31 \\
\hline & 1.0 & 0.49 & 0.64 & 0.66 & 1.34 & -0.74 & 1.34 & -0.09 \\
\hline & 1.5 & 0.06 & 0.79 & 0.80 & 1.16 & -1.01 & 1.38 & 0.07 \\
\hline & 2.0 & -0.02 & 0.81 & 0.76 & 0.95 & -0.50 & 1.32 & 0.13 \\
\hline \multirow{5}{*}{ Chinese } & 0.0 & 1.07 & 2.47 & 0.93 & 0.72 & 1.40 & 2.67 & 1.68 \\
\hline & 1.0 & 1.29 & 3.08 & 1.57 & 1.88 & 2.68 & 2.13 & 2.35 \\
\hline & 1.5 & 1.35 & 2.95 & 1.97 & 2.34 & 3.01 & 2.17 & 2.35 \\
\hline & 2.0 & 0.85 & 2.95 & 2.05 & 2.18 & 3.22 & 1.94 & 2.49 \\
\hline & 2.5 & 0.58 & 3.40 & 2.02 & 2.55 & 3.57 & 1.89 & 2.55 \\
\hline \multirow{6}{*}{ Peruvian } & 0.0 & 0.80 & 2.28 & 1.41 & 1.52 & 1.67 & 2.32 & 1.63 \\
\hline & 1.0 & 0.72 & 1.37 & 1.16 & 0.85 & 1.02 & 1.39 & 0.96 \\
\hline & 1.5 & 1.07 & 2.23 & 1.31 & 1.33 & 1.46 & 1.38 & 1.22 \\
\hline & 2.0 & 0.33 & 1.48 & 0.75 & 0.95 & 1.38 & 1.05 & 0.69 \\
\hline & 2.5 & 0.28 & 1.28 & 0.51 & 0.77 & 1.06 & 0.57 & 0.33 \\
\hline & 3.0 & 0.27 & 1.51 & 0.30 & 0.92 & 1.08 & 1.18 & 0.45 \\
\hline
\end{tabular}

In summary, we can state the following: The colour agent content decreases for initial samples $(0 \mathrm{~g})$, and does not differ significantly for samples with added oleoresin. The decrease of colour agent content varied between 22 and 51 percent; the average reduction was 33 percent. The values of colour difference for initial samples and those for samples with added oleoresin do not differ significantly. During storage time, the colour of paprika samples became brighter and less saturated. 


\section{References}

[1] J. Banout. P. Ehl, J. Havlik, B. Lojka, Z. Polesny, V. Verner, Design and performance evaluation of a double-pass solar drier for drying of red chilli (Capsicum annum L.). Solar Energy, 85. (2011) 506-515.

[2] M. B. Chetti, G. T. Deepa, T. A. Roshny, M. C. Khetagoudar, D. S. Uppar, C. M. Navalgatti, Influence of vacuum packaging and long-term storage on quality of whole chilli (Capsicum annuum L.). J Food Sci Technol, 51. (2014) 2827-2832.

[3] Q. Chen, H. K. Koh, J. B. Park, Color evaluation of red pepper powder. Transaction-of-the-ASAE, 42. (1999) 749-752.

[4] M. P. Doymaz, Hot-air drying characteristics of red pepper. Journal of Food Engineering, 55. (2002) 331-335.

[5] M. Drdak, G. Greif, P. Kusy, Comparison between the sensory and spectrophotometric method for determination of colour of paprika powder. Nahrung, 33. (1989) 737-742.

[6] Zs. H. Horváth, Procedure for setting the colour characteristics of paprika grist mixtures. Acta Alimentaria, 36. (2007) 75-88.

[7] M. Fekete-Halász, J. Kispéter, Effect of irradiation on colour of ground paprika. Acta Alimentaria, 25. (1996) 189-193.

[8] L. Horváth, K. Kaffka, Instrumental colorimetry of red-pepper grist. Mérés és Automatika, 21. (1973) 341-348.

[9] Zs. H. Horváth, C. Hodúr, The colour of paprika powders with different moisture content. International Agrophysics, 21. (2007) 67-72.

[10] T. Huszka, M. Halász-Fekete, Gy. Lukács, Colour tolerance of redpepper powders. Hungarian Scientific Instruments, 60. (1995) 43-47.

[11] R. Hunter, The measurement of appearance. Wiley Press, New York (1987).

[12] S. Kim, J. Park, I. K. Hwang, Quality attributes of various varieties of Korean red pepper powder (Capsicum annum L.) and colour stability during sunlight exposure. Journal of Food Science, 67. (2004) 29572961. 
[13] M. Minguez-Mosquera, A. Perez-Galvez, J. Garrodo-Fernandez, Carotenoid content of the varieties Jaranda and Jariza (Capsicum annum L.) and response during the industrial slow drying and grinding steps in paprika processing. Journal of Agricultural and Food Chemistry, 48. (2000) 2972-2976.

[14] F. Navarro, J. Costa, Evaluation of paprika pepper color by Trisestimulus Colorimetry. Revista Espanola de Ciencia y Tecnologia de Alimentos, 33. (1993) 427-434.

[15] J. M. Nieto-Sandoval, J. A. Fernandez-Lopez, L. Almela, J. A. Munoz, Dependence between apparent colour and extractable colour in paprika. Colour Research and Application, 24. (1999) 93-97.

[16] J. H. Park, C. S. Kim, The stability of colour and antioxidant compounds in paprika (Capsicum annuum L) powder during the drying and storing process. Food Science and Biotechnology, 16. (2007) 187192.

[17] M. Ramesh, W. Wolf, D. Tevini, G. Jung, Influence of processing parameters on drying of spice paprika. Journal of Food Engineering, 49. (2001) 63-72.

[18] J. H. Shin, H. L. Chung, J. K. Seo, J. H. Sim, C. S. Huh, S. K. Kim, Y. J. Beak, Degradation kinetics of capsanthin in paprika (Capsicum annuum L.) as affected by heating. Journal of Food Science, 66. (2001) $15-19$.

[19] S. Simal, C. Garau, A. Femenia, C. Rosselló, Drying of red pepper (Capsicum Annum): water desorption and quality. International Journal of Food Engineering, 1. (2005) 1. DOI: 10.2202/1556-3758.1022.

[20] H. Topuz, M. K. Feng, The effect of drying method and storage on colour characteristics of paprika. Food Science and Technology, 42. (2009) 1667-1673.

[21] C. D. Topuz, K. S. Özdemir, H. Feng, M. Kushad, Influence of different drying methods on carotenoids and capsaicinoids of paprika ( $\mathrm{Cv}$., Jalapeno). Food Chemistry, 129. (2011) 860-865. 